\title{
Historical landscape structure affects plant species richness in wet heathlands with complex landscape dynamics
}

\author{
Sara Cristofoli ${ }^{1}$, Arnaud Monty*, Grégory Mahy \\ Biodiversity and Landscape Unit, Gembloux Agrio-Bio Tech, University of Liege, Passage des Déportés, 2, BE-5030 Gembloux, Belgium
}

\section{A R T I C L E I N F O}

\section{Article history:}

Received 4 March 2009

Received in revised form 30 April 2010

Accepted 28 July 2010

\section{Keywords:}

Fragmentation

Extinction debt

Plant species richness

Land-use history

\begin{abstract}
A B S T R A C T
The spatio-temporal dynamics of wet heathlands from two landscapes in high Ardenne (Belgium), as well as the consequences of such dynamics on plant communities were investigated. Past and present destruction and origin of habitat patches have resulted in a complex network of different aged habitat patches. Current specialist and generalist species richness were assessed in 59 patches and analyzed with respect to present and past patch spatial metrics (controlled for habitat quality). Current patch area affected specialist species richness and current patch connectivity influenced both specialist and generalist species richness. Thirteen of the 59 patches were historical patches, i.e. patches that have remained since the 1770s. In these historical patches, including past landscape structure in the analysis explained more of the variability in current species richness than the current landscape structure alone, suggesting the existence of an extinction debt.
\end{abstract}

(ㄷ) 2010 Elsevier B.V. All rights reserved.

\section{Introduction}

Human activities have impacted landscape structure and function worldwide, and are currently the main factor dictating landscape dynamics in many regions (Baudry and Tatoni, 1993; Goudie, 2005). A common characteristic of human-driven landscape alteration is the destruction and fragmentation of natural and semi-natural habitats (Balmford and Bond, 2005). The most detrimental consequences of landscape fragmentation for plant and animal species includes loss of suitable habitat, progressive habitat patch isolation and increased edge effects at the expense of interior habitats (Andrén, 1994; Fahrig, 2003). Local species extinction rates can be increased and local colonization inhibited due to these pressures on remnant habitat, which consequently reduces species richness. On the other hand, dynamics within humandriven landscapes may also lead to the creation of new habitat patches, resulting in conditions conducive to spontaneous colonization by species from natural or semi-natural environments. Under these conditions, the potential exists for range extension of isolated populations (Collins et al., 1985; Krüger et al., 2002).

From a geographical context, plant species diversity within a habitat type is largely dependent on spatio-temporal landscape

\footnotetext{
* Corresponding author. Tel.: +32 0 81622546; fax: +32 081614817.

E-mail addresses: cristofoli.s@lifelomme.be (S. Cristofoli), arnaud.monty@ulg.ac.be (A. Monty),G.mahy@ulg.ac.be (G. Mahy).

1 Present address: LIFE-Lomme project, Rue de Villance, 90, BE-6890 Libin, Belgium.
}

patterns, both at the landscape and habitat patch scale (Cousins and Eriksson, 2002; Ricklefs, 2004; Turner et al., 2001). Conceptually, a positive relationship between patch area and species richness has been well established (Bastin and Thomas, 1999; Bruun, 2000; Honnay et al., 1999a). It emphasizes that species in small patches are more susceptible to area-dependent influences, such as genetic and demographic stochasticity (Holsinger, 2000; Pimm et al., 1988). The negative effects of area loss and resulting fragmentation can be reduced when connectivity among habitats is sufficient to maintain propagule dispersal among populations (Brown and Kodric-Brown, 1977; Piessens and Hermy, 2006). However, species response to landscape change exhibits a time lag, and communities which experience habitat destruction and/or creation of new habitat patches may therefore face two unbalanced states with regard to patch (spatial) characteristics: (1) extinction debt (Hanski and Ovaskainen, 2002), or (2) colonization credit (Cristofoli et al., in press). These terms are respectively defined as the mean number of species yet (1) to go extinct in a patch, or (2) to colonize a patch. Both states follow landscape change, and continue until species richness reaches equilibrium with the new spatial properties of the patch. Such unbalanced conditions have important implications for species conservation, since long-term species richness may be over- or underestimated on the basis of current records of species number (Hanski and Ovaskainen, 2002).

Previously widespread wet heathlands and closely associated habitats (i.e. poor fens and bogs) have experienced a marked decline in Western Europe since the 19th century (Webb, 1998). Human activities are largely responsible for this decline, and include peat extraction, anthropogenic afforestation (mainly Norway Spruce 
Picea abies [L.] Karst) and the abandonment of traditional agropastoral practices replaced by widespread agriculture (Clicheroux, 1985; Petit and Lambin, 2002; Webb, 2002). This has resulted in habitat fragmentation as well as homogenisation of the landscape matrix. However, thanks to current forest management and successful restoration approaches, wet heathland patches and poor fens have been routinely established (Cristofoli et al., in press). Despite these achievements, a consequence of the dynamic nature of wet heathland communities is the potential for unbalanced states resulting from an extinction debt or a colonization credit. Wet heathlands, poor fens and bogs support very specialised plant and animal species (Lambinon et al., 2004; Rodwell, 1991) and are considered key habitats for biodiversity conservation in the European Community (Annex I of the Habitat Directive $92 / 43 / E E C)$. Nevertheless, few studies have examined the relationships between species distribution patterns and landscape structure (but see Piessens and Hermy, 2006; Piessens et al., 2005); and studies specifically addressing extinction debt in these habitats are lacking. Piessens and Hermy (2006) suggested that a low species loss rate in highly fragmented north Belgium heathlands may be the result of an extinction debt, but provided no direct test for this hypothesis. However, some studies in semi-natural grasslands have reported evidence of an extinction debt (Gustavsson et al., 2007; Helm et al., 2006) but other studies have not provided supporting data (Adriaens et al., 2006).

The aims of the present study were to investigate and assess the consequences of past and present habitat dynamics on plant community patterns in two high Ardenne landscapes (Belgium). A previous study demonstrated that recently created wet heathland patches did not experience a colonization credit, i.e. species richness in the two landscape patches were similar to that expected at equilibrium given the patch spatial structure (Cristofoli et al., in press). In the present study, we examined the potential for an extinction debt in wet heathland patches.

Landscape dynamics are complex. Therefore, we first provided a detailed analysis of wet heathlands and closely associated habitat spatial and temporal landscape changes over the past 250 years. Furthermore, the distinct contributions of habitat destruction and origins to landscape dynamics were investigated for four time periods. We subsequently analyzed the relationships between present and past landscape structure and plant species richness, and tested for an extinction debt in historical wet heathland patches.

\section{Materials and methods}

\subsection{Study site}

The study site was $797 \mathrm{~km}^{2}\left(50^{\circ} \mathrm{N}, 5^{\circ} \mathrm{E}\right)$ in size and included two landscapes in the Belgian Ardenne, separated by a large valley (Plateau de Saint-Hubert and Plateau des Tailles, 400-650 m a.s.l., respectively; Fig. 1). Although highly fragmented, this region supports one of the last substantial areas of bogs, poor fens and wet heathlands in Belgium. The delimitation of these habitats relies on peat depth and is restricted to nutrient poor, relatively acidic and poorly drained soil conditions (Bakker and Berendse, 1999; Gimmingham, 1972). The habitats are developed under azonal climatic conditions characterised by cold winters (average winter temperature: $0.4{ }^{\circ} \mathrm{C}$ ) and high precipitation (1150 mm/year), typical of Belgian plateaus.

\subsection{Landscape analysis}

Current (2006) and past landscape structure of target habitats were assessed using geographic information systems (GIS, ArcGIS 8.3, ESRI, 2002). Five topographical maps dating from the

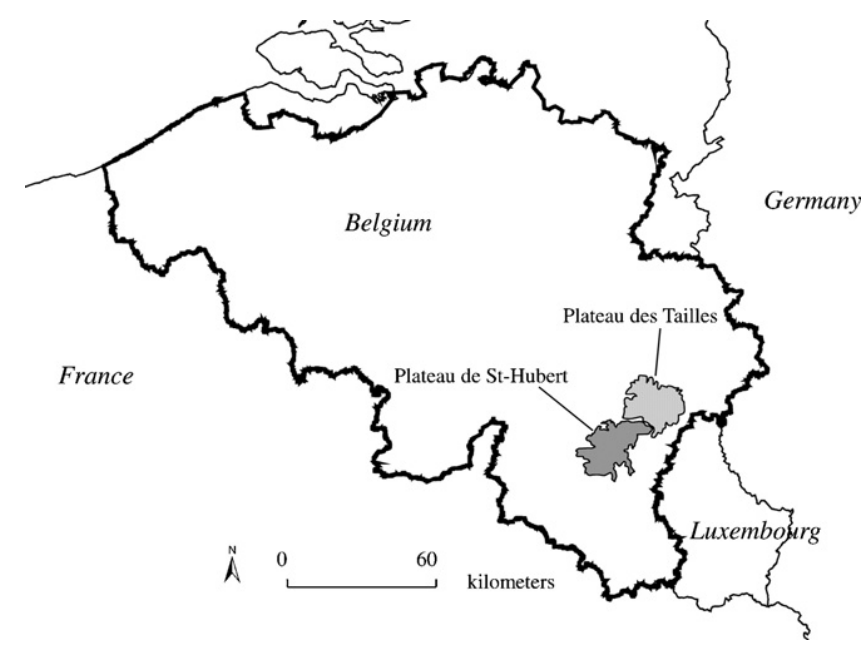

Fig. 1. Study area location (Plateau de Saint-Hubert and Plateau des Tailles) in Belgium.

(1) 1770s (1:11 520; De Ferraris); (2) 1880s (1:20 000; Belgian Military Cartographic Institute); (3) 1950s (1:20 000; Belgian National Geographical Institute); (4) 1970s (1:10 000; Belgian National Geographical Institute); and (5) 2006 (1:10000; Regional Research Centre for Nature, Forest and Wood) were digitised. Although the cartographical documents we used to evaluate landscape dynamics spanned a long period of time, the date ranges can be considered comparable in terms of spatial resolution. Documents that covered the 1880s, 1950s, 1970s and 2006 covered minimal patch area of similar size $\left(100 \mathrm{~m}^{2}\right)$. The cartographical document from the 1770 s was the first topographical map of the region. We found the document to exhibit decreased accuracy yet hold valuable information regarding early landscape characteristics. Feature classes were made homogeneous across the multiple maps and three classes, i.e. bogs, poor fens and wet heathlands were retained to delimit habitat patches. However, the first four maps did not distinguish wet and dry heathlands because soil drainage was not always explicitly circumscribed. A potential habitat map for target communities was subsequently created based on soil properties (derived from the Walloon digital soil map, FSAGx, 2004) and altitude. Heathland patches located outside potential sites (i.e. xeric and mesic heathlands) were excluded from the study. Heathlands, poor fens and bogs are intricate communities and form a mosaic of habitats; therefore the respective habitat maps were merged to form one single habitat category, termed a 'complex of wet heathlands'.

The spatial structure of target habitats was assessed using the following quantitative metrics, estimated for each of the five map dates and for each plateau: total habitat area, number of patches, patch area, patch connectivity (Hanski's $S$ index in the Incidence Function Model index (Hanski, 1994), referred to as IFM $S$ index) and patch isolation (Euclidian distance from a patch border to its 'nearest neighbour'). The IFM $S$ index was computed using edge-toedge distances between all the patches, i.e. between all the possible source populations in the landscape (Moilanen and Nieminen, 2002). IFM $S$ index calibration parameters followed the recommendations and values of Moilanen and Nieminen (2002) used in recent plant studies, i.e. $\alpha=1$ (Adriaens et al., 2006; Bruun, 2000; Kolb and Diekmann, 2005; Lindborg, 2007). The metrics were calculated separately for new and old patches for each map date. For a given date, an old patch was defined as a habitat patch observed at the study site that was also present on the former map, and a new patch was one absent on the former map but currently observed at the study site. We determined the annual rate of target habitat destruction or creation during four time periods (1770-1880; 1880-1950; 1950-1970 and 1970-2006) as habitat contraction (destroyed area 
in ha) or expansion (created area in ha) during the period divided by the number of years in the period.

\subsection{Species analysis}

A survey was carried out in 2006 to identify vascular plant species richness and included 59 habitat patches of wet heathland complexes in the study area. We did not evaluate all the patches identified on the 2006 map because a large proportion of patches were very small and dominated by edge effects. We expected species richness would be influenced predominantly by patch quality rather than patch spatial properties (area, connectivity) in these small patches. Therefore, only patches larger than 0.3 ha were investigated. Two estimates of species diversity were derived for each patch: specialist species richness $\left(R_{\mathrm{SPEC}}\right)$ and generalist species richness $\left(R_{\mathrm{GEN}}\right)$. A specialist species list was based on a regional classification of plant communities (Duvigneaud, 2001; Lebrun et al., 1949) and on expert assessments. During the field surveys, habitat quality was estimated for each patch and included indicators of habitat configuration and disturbance level. Habitat configuration was evaluated by recording the four life cycle stages (pioneer, building-up, mature, degenerative) observed for Calluna vulgaris [L.] Hull (Ericaceae), \% bare soil cover, \% Ericaceae cover and \% Sphagnum spp. cover. Ericaceae (including C. vulgaris) and Sphagnum spp. are indicator species for the wet heathlands complex; and the presence of the four life cycle stages of $C$. vulgaris indicates a well-structured population (Watt, 1955). Indicators of habitat disturbance (Bakker and Berendse, 1999) were determined by \% ligneous species cover, \% Molinia caerulea [L.] Moench cover, \% Pteridium aquilinum [L.] Kuhn cover and \% Juncus effusus L. cover. A principal component analysis (PCA) was employed to summarize habitat quality variables and control for intercorrelation among variables. To control for the effect of patch quality, patch scores on the first canonical axis were introduced as a covariate in all the further analyses.

First, partial (i.e. patch quality as a covariate) simple linear regressions were used to detect possible effects of each single explanatory variable. Second, in order to control for the effect of patch connectivity while testing the effect of patch area, the IFM $S$ index was included as a covariate in a partial simple linear regression. Similarly, in addition to patch quality, patch area was included as a covariate while testing the effect of patch connectivity.

Partial multiple (best-subset) regressions between species richness estimates and present landscape structure metrics were computed. Models of multiple regression, called Best Present Model (BPM), were further used with past landscape structure (see below) to test for an extinction debt. Patch area, IFM $S$ index and nearest neighbour were included as landscape structure metrics. To improve homoscedasticity, patch area and nearest neighbour were $\log$ transformed, and the IFM $S$ index was square root transformed.

The importance of past landscape structure on current species richness was evaluated by analysing only patches identified on the five maps, i.e. patches present in 2006 that could be traced to the 1770s. This served to test if past landscape structure added significant information to the BPM to explain current species richness. If it did, we hypothesized that species richness is not yet at equilibrium with the present landscape structure and suggest an extinction debt is present. We tested for significant effects of past patch structure metrics on present species richness estimates via multiple linear regressions. For each possible model (i.e. 16 models: four metrics in reference to four dates), the BPM variables (see above) were set as obligatory variables. The proportion of patch area loss from the previous period was added as a historic patch spatial variable. All the analyses were performed with MINITAB 14.0 (Minitab 2002, Pennsylvania) and Canoco 4.5 (Canoco 2002, New York).

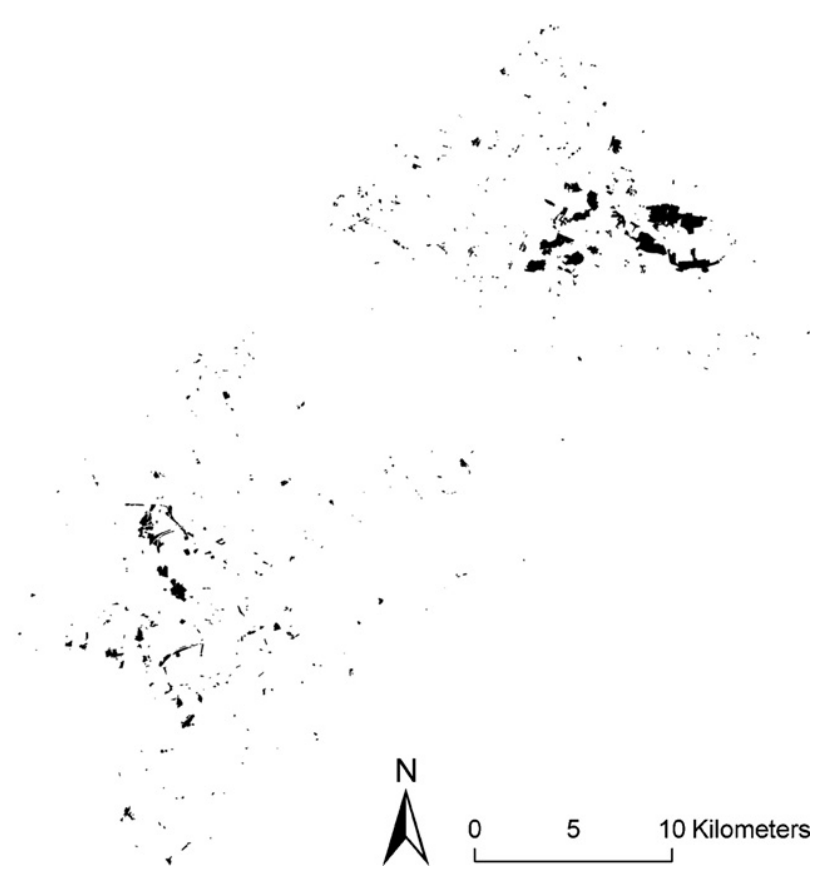

Fig. 2. Distribution of the wet heathlands complex in 2006 in the two high plateaus.

\section{Results}

\subsection{Landscape analysis}

The target habitats have experienced severe fragmentation over the past 250 years (Fig. 2 represents the current fragmentation). The total area of target habitat decreased by $93.76 \%$ and $93.51 \%$ on the Plateau de Saint-Hubert and Plateau des Tailles, respectively between the 1770s and 2006. Over the same time period, mean patch area decreased by $99.52 \%$ and $99.46 \%$ and the mean IFM $S$ index decreased by a respective $97.60 \%$ and $98.22 \%$ on the Plateau de Saint-Hubert and Plateau des Tailles (Fig. 5). However, in addition to the general fragmentation pattern, the dynamics of the two landscapes resulted from a complex combination of destruction and origin of target habitat patches (Figs. 3 and 4). The annual rates of habitat destruction and origin indicated that two different time periods characterized landscape change, with the 1950s a crucial date.

Prior to the 1950s, the combination of habitat destruction and creation resulted in a net loss of habitat area with a maximal annual area loss of 95.91 ha/year between the 1880s and the 1950s (Tailles, Fig. 4). In the two landscapes, the number of patches first increased tremendously due to dividing a few number of large patches into numerous smaller patches (Fig. 3(a)). Subsequently, between the 1880s and the 1950s, the number of patches decreased with patch destruction exceeding the parcelling out of large patches into numerous smaller patches. However, during the same period, the creation of new habitat patches in the landscape still contributed to the origin of target habitat. In the 1950 s, $69.6 \%$ of the target habitat area was distributed into new habitat patches (SaintHubert, Fig. 3(b)). During this period, the mean patch IFM $S$ index exhibited a decrease in patch connectivity (Fig. 5(b)).

The 1950s through 2006 experienced a net increase by $194.60 \%$ (Saint-Hubert) and 29.34\% (Tailles) in habitat area (Fig. 3(b)), with a maximum annual creation rate of 16.91 ha/year between the $1950 \mathrm{~s}$ and 1970s (Saint-Hubert, Fig. 4). This was due to the creation of numerous small patches, as indicated by an increase in patch number and decrease in mean patch area (Figs. 3(a) and 5(a)). The mean IFM $S$ index and nearest neighbour values indicated an increase in connectivity over the period (Fig. 5(b) and (c)). 

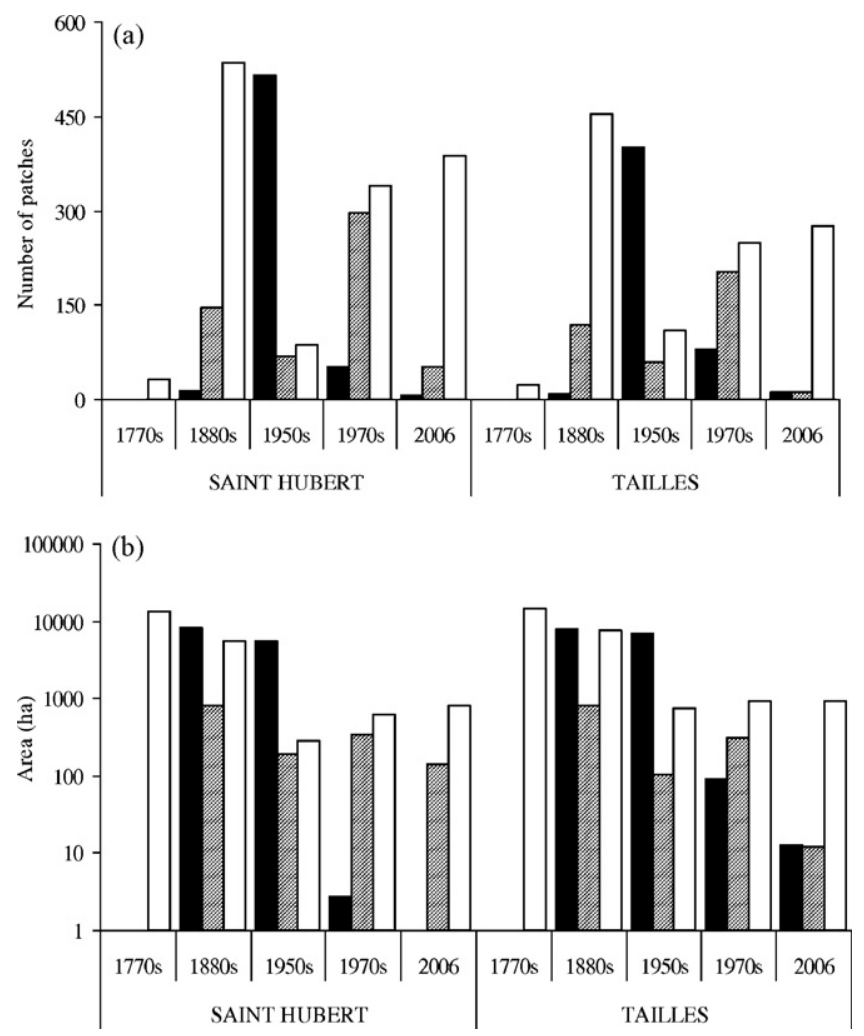

Fig. 3. Total (white) number of patches (a) and area of wet heathlands (b) from the 1770s to 2006 in two landscapes in the high Ardenne (Belgium) based on recent and historical maps. Number of patches and area destroyed (black) and created (grey) over the same period.

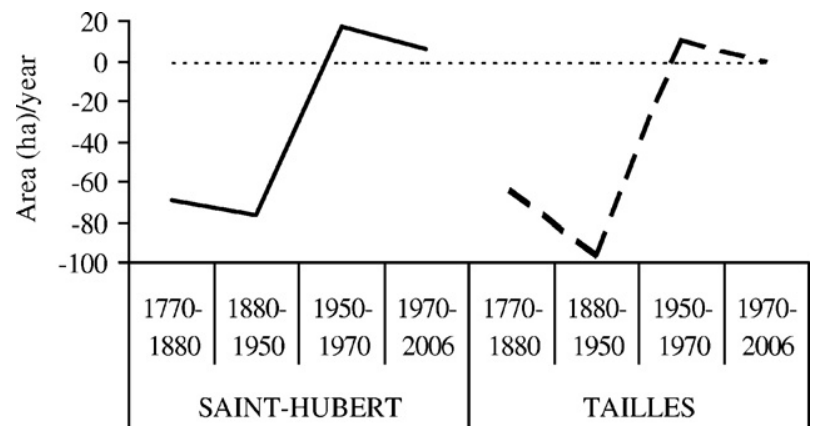

Fig. 4. For each period, annual decrease or increase of the total patch area of the wet heathlands complex in the two landscapes.

The target habitat dynamics over the past 250 years resulted in a complex mixture of new and old patches of different ages. For example, in 2006, patches persisting since the 1770s represented only $8.4 \%$ of all the patches in the landscape in terms of patch number, or $9.0 \%$ old patches (Table 1 ). However, they repre-
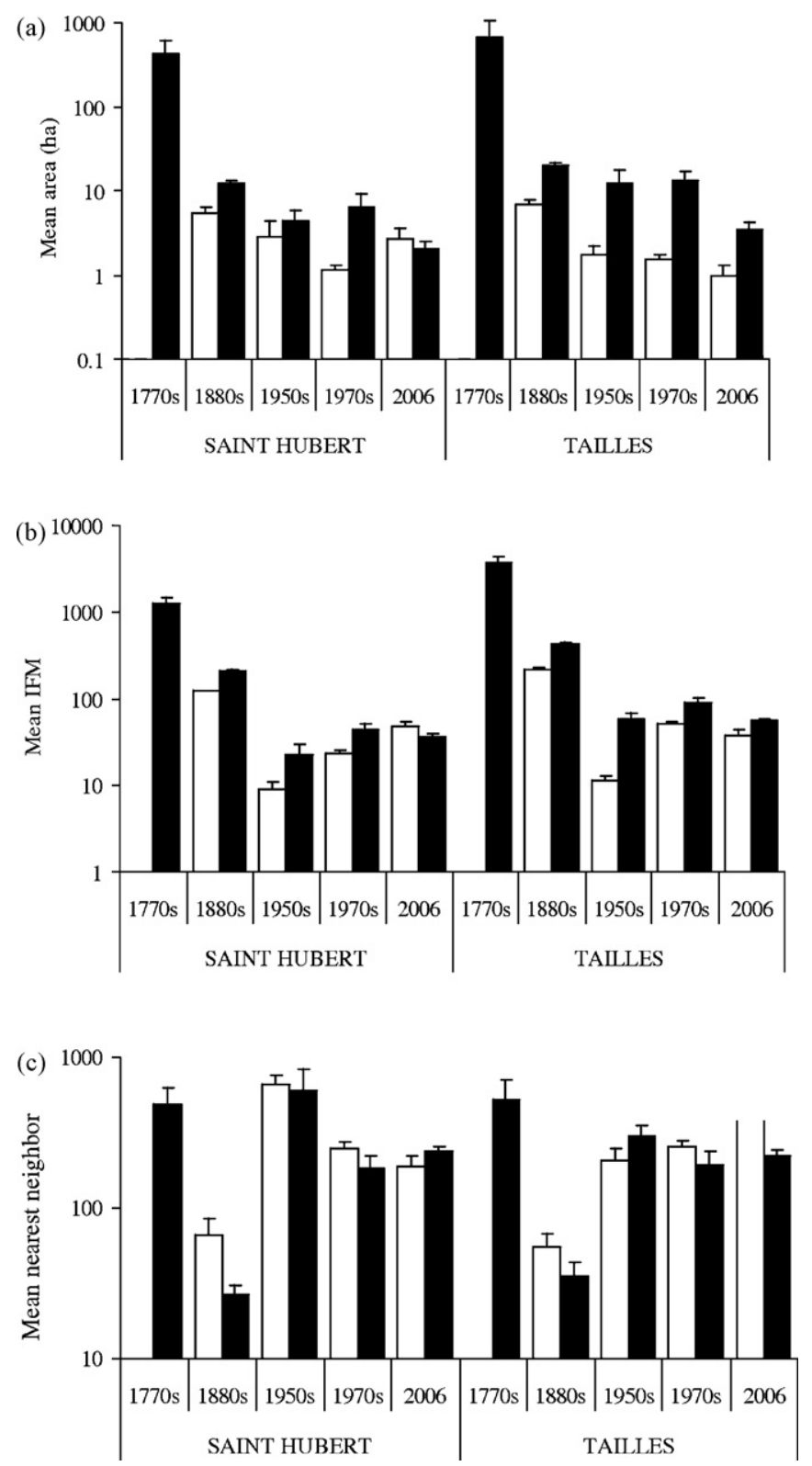

Fig. 5. Mean (standard error) patch area (a), connectivity (IFM index) (b) and nearest neighbour (c) of old (black) and new patches (white), in the two landscapes from the 1770 s until 2006. An old patch was defined as a patch of habitat present at a specific date and at the previous date, whereas a new patch was absent at the previous date.

sented $32.6 \%$ of the total area of the target habitat. In 2006, most old patches (80.5\%) were established between the 1950s and the 1970s. For each time period, old and new habitat patches differed in their mean spatial metrics. For all the dates (with the exception of 2006), the mean area and the IFM $S$ index of old patches were

Table 1

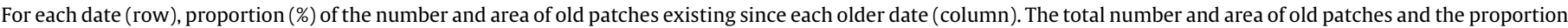
of new habitat patches for each date.

\begin{tabular}{|c|c|c|c|c|c|c|c|c|c|c|c|c|}
\hline & \multirow[t]{2}{*}{ Patches total \# } & \multicolumn{4}{|c|}{ \% \# Existing since } & \multirow[t]{2}{*}{ \% New } & \multirow[t]{2}{*}{ Patches total ha } & \multicolumn{4}{|c|}{$\%$ ha existing since } & \multirow[t]{2}{*}{ \% New } \\
\hline & & $1770 \mathrm{~s}$ & $1880 \mathrm{~s}$ & $1950 \mathrm{~s}$ & $1970 \mathrm{~s}$ & & & $1770 \mathrm{~s}$ & $1880 \mathrm{~s}$ & $1950 \mathrm{~s}$ & $1970 \mathrm{~s}$ & \\
\hline $1770 \mathrm{~s}$ & 53 & & & & & 0.0 & 27707 & & & & & 0.0 \\
\hline $1880 \mathrm{~s}$ & 988 & 73.3 & & & & 26.7 & 13088 & 87.7 & & & & 12.3 \\
\hline $1950 \mathrm{~s}$ & 197 & 27.9 & 4.1 & & & 68.0 & 1007 & 56.2 & 11.9 & & & 32.0 \\
\hline $1970 \mathrm{~s}$ & 589 & 5.3 & 2.2 & 7.0 & & 85.6 & 1559 & 38.0 & 6.1 & 14.4 & & 41.6 \\
\hline 2006 & 663 & 8.4 & 2.3 & 6.8 & 72.5 & 10.0 & 1765 & 32.6 & 4.6 & 13.5 & 40.9 & 8.5 \\
\hline
\end{tabular}


Table 2

Pearson's correlation coefficients between patch scores on the PCA first four canonical axes and quality/disturbance variables.

\begin{tabular}{lllll}
\hline Habitat quality indicators & Axis 1 & Axis 2 & Axis 3 & axis 4 \\
\hline nb. life cycle stages C. vulgaris & 0.792 & 0.124 & 0.301 & 0.107 \\
Bare soil [\%] & 0.506 & 0.128 & 0.020 & 0.499 \\
Ericaceae [\%] & 0.693 & 0.187 & 0.193 & 0.035 \\
Sphagnum spp. [\%] & 0.033 & 0.775 & 0.013 & 0.103 \\
ligneous species [\%] & 0.184 & 0.418 & 0.684 & 0.388 \\
M. caerulea [\%] & 0.678 & 0.085 & 0.095 & 0.487 \\
P. aquilinum [\%] & 0.235 & 0.607 & 0.090 & 0.552 \\
J. effusus [\%] & 0.249 & 0.423 & 0.792 & 0.151 \\
\hline
\end{tabular}

greater than for new patches. Mean nearest neighbour results for old and new patches showed similar values (Fig. 5).

\subsection{Species diversity}

Specialist species richness ranged from 5 to 30 species and generalist species richness ranged from 6 to 33 species. Landscape analysis results indicated that the wet heathland complex dynamics were very similar on both plateaus. Therefore, data from the Plateau de Saint-Hubert and Plateau des Tailles were pooled for the species analysis.

The PCA first canonical axis was based on habitat quality variables from the 59 patches we examined (Eigenvalue: 1.98). The axis was negatively correlated with bare soil cover $(r=-0.678)$ and positively correlated with $M$. caerulea and Ericaceae cover, and the number of $C$. vulgaris life-cycle stages (respective $r=0.678,0.693$ and 0.792 ). Estimates of specialist species richness were significantly positively correlated with patch scores on the first canonical axis $\left(r^{2}=20.0 \% ; P<0.001\right)$, but no significant correlation was found for generalist species richness $\left(r^{2}=0.8 \% ; P=0.491\right)$.

The analysis of current patch spatial metrics (controlled for habitat quality) showed a significant positive regression between the two species richness estimates and patch IFM $S$ index. However, only $R_{\text {SPEC }}$ was significantly related to patch area (Table 2 ). This relationship was maintained even when controlling area for IFM $S$ index. In contrast, patch IFM $S$ index controlled for area indicated a marginally significant relationship with $R_{\mathrm{GEN}}$. Patch IFM $S$ index and nearest neighbour were significantly correlated $(r=-0.412$; $P=0.001)$, however BPM based on all the patches $\left(n=59 ; \mathrm{BPM}_{59}\right)$ included both variables for generalist species richness $\left(R^{2}=10.2\right.$; $P=0.049)$. Only patch area was included for specialist species richness $\left(r^{2}=45.0 \% ; P<0.001\right.$; Table 3$)$.

Thirteen of the 59 patches surveyed in 2006 have remained since the 1770 s throughout the entire study site. To test if the 13 patches were a representative subset of the 59 patches, the best present model associating species richness to present patch spatial structure variables (BPM) were re-computed for the 13 patches. The results were congruent whether BPMs were built with $13\left(\mathrm{BPM}_{13}\right)$ or 59 patches $\left(\mathrm{BPM}_{59}\right)$. The analysis included patch area in the

Table 3

Partial simple linear regressions between species richness estimates and patch spatial structure (patch quality is set as a covariable).

\begin{tabular}{llllll}
\hline & \multicolumn{2}{l}{$R_{\mathrm{GEN}}$} & & \multicolumn{2}{l}{$R_{\mathrm{SPEC}}$} \\
\cline { 2 - 3 } Variable & $r^{2}$ & $P$ & & $r^{2}$ & $P$ \\
\hline Area & 2.5 & 0.228 & & 45.0 & $<0.001$ \\
Area $\times$ IFM & 0.2 & 0.767 & & 27.7 & $<0.001$ \\
IFM & 7.5 & 0.036 & & 19.7 & $<0.001$ \\
IFM $\times$ Area & 5.1 & 0.085 & & 2.4 & 0.238 \\
Nearest neighbour & 6.9 & 0.045 & & 0.3 & 0.666 \\
\hline
\end{tabular}

$\times$, states for'excluding the effect of'; $R_{\mathrm{GEN}}$, generalist species richness; $R_{\mathrm{SPEC}}$, specialist species richness; IFM, patch connectivity.
Table 4

Partial multiple (best-subset) regressions between species richness estimates and patch spatial structure (patch quality is set as a covariable).

\begin{tabular}{rlrr}
\hline & Variables included in the model & \multicolumn{1}{c}{$R^{2}$} & \multicolumn{1}{c}{$P$} \\
\hline $\mathrm{BPM}_{59}$ & & & \\
$R_{\mathrm{GEN}}$ & IFM (+); nearest neighbour (-) & 10.2 & 0.049 \\
$R_{\mathrm{SPEC}}$ & Area (+) & 45.0 & $<0.001$ \\
$\mathrm{BPM}_{13}$ & & & \\
$R_{\mathrm{GEN}}$ & IFM (+) & 0.7 & 0.780 \\
$R_{\text {SPEC }}$ & Area (+) & 48.5 & 0.008 \\
\hline
\end{tabular}

$R_{\mathrm{GEN}}$, generalist species richness; $R_{\mathrm{SPEC}}$, specialist species richness; IFM, patch connectivity. BPM $\mathrm{B}_{59}$, Best Present Model based on the entire set of patches $(n=59)$. $\mathrm{BPM}_{13}$, Best Present Model based on patches existing from the 1770s until 2006 $(n=13)$.

$\mathrm{BPM}_{13}$ using $R_{\mathrm{SPEC}}$. Results indicated similar $r^{2}$ values for $R_{\mathrm{SPEC}}$ in both $\mathrm{BPM}_{13}$ and $\mathrm{BPM}_{59}$ (Table 4).

The 13 patches were subsequently analyzed to assess the relationship between past landscape structure and present species richness. Present patch area $\left(R_{\mathrm{SPEC}}\right)$ was retained as obligatory independent variables in multiple regressions with past landscape metrics to test for additional significant information. The $\mathrm{BPM}_{13}$ for specialist species richness $\left(r^{2}=48.5 \% ; P=0.008\right)$ was improved by including 1970 patch area or patch area loss between the $1970 \mathrm{~s}$ and $2006\left(R^{2}=79.1 \% ; P<0.001 ; R^{2}=80.7 \% ; P<0.001\right.$, respectively $)$. Patch area and area loss in the 1970 s were not significantly correlated (Pearson $=0.272 ; P=0.369$ ).

$\mathrm{BPM}_{13}$ using $R_{\mathrm{GEN}}$ included the IFM $S$ index. Similarly, the IFM $S$ index was maintained as an obligatory independent variable in multiple regressions with past landscape metrics. The addition of the 1950 s patch nearest neighbour to $\mathrm{BPM}_{13}$ explained significantly more of the variability in current generalist species richness than the current IFM $S$ index alone (Table 5 ). The coefficient of determination increased from $0.7 \%(P=0.780)$ with present patch IFM $S$ index alone to $61.0 \%(P=0.009)$ when adding patch nearest neighbour from the 1950s. Spatial metrics associated with the $1770 \mathrm{~s}$ patch characteristics were not included in any models because the 13 patches included in the analyses were part of only two single large patches, one on each plateau.

\section{Table 5}

Partial multiple regressions between species richness and present/past spatial structure variables. Patch area in 2006 is set as obligatory variables in the $\mathrm{R}_{\mathrm{TOT}}$ and $\mathrm{R}_{\mathrm{SPEC}}$ model whereas patch IFM is an obligatory variable in the $R_{\mathrm{GEN}}$ model.

\begin{tabular}{|c|c|c|c|c|}
\hline \multirow{2}{*}{$\begin{array}{l}\text { Date } \\
\text { Variable }\end{array}$} & \multicolumn{2}{|l|}{$R_{\mathrm{GEN}}$} & \multicolumn{2}{|l|}{$R_{\mathrm{SPEC}}$} \\
\hline & $r^{2}$ & $P$ & $r^{2}$ & $P$ \\
\hline BPM13 & 0.7 & 0.780 & 48.5 & 0.008 \\
\hline \multicolumn{5}{|l|}{ 1980s } \\
\hline Area & & ns & 80.7 & $<0.001$ \\
\hline Area loss & & ns & 79.1 & $<0.001$ \\
\hline IFM & & ns & & ns \\
\hline Nearest neighbour & & ns & & ns \\
\hline \multicolumn{5}{|l|}{$1950 s$} \\
\hline Area & & ns & & ns \\
\hline Area loss & & ns & & ns \\
\hline IFM & & ns & & ns \\
\hline Nearest neighbour & 61.0 & 0.009 & & ns \\
\hline \multicolumn{5}{|l|}{$1880 s$} \\
\hline Area & & ns & & ns \\
\hline Area loss & & ns & & ns \\
\hline IFM & & ns & & ns \\
\hline Nearest neighbour & & ns & & ns \\
\hline \multicolumn{5}{|l|}{1770 s } \\
\hline Area & & ns & & ns \\
\hline Area loss & & ns & & ns \\
\hline IFM & & ns & & ns \\
\hline Nearest neighbour & & ns & & ns \\
\hline
\end{tabular}

$\mathrm{BPM}_{13}$, Best Present Model based on patches existing from the 1770s until 2006 $(n=13) ; R_{\mathrm{GEN}}$, generalist species richness; $R_{\mathrm{SPEC}}$, specialist species richness; IFM, patch connectivity. 


\section{Discussion}

\subsection{Spatio-temporal dynamics of habitat patches}

Studies of temporal dynamics in temperate, open, and seminatural habitats have systematically addressed general patterns of area decrease and isolation increase resulting from habitat fragmentation (Adriaens et al., 2006; Helm et al., 2006; Lindborg and Eriksson, 2004), whereas little attention has been paid to the potential contribution of secondary habitat origins through time (but see Arroyo-Mora et al., 2004; Jacquemyn et al., 2003). Our study demonstrated that spatial changes in wet heathlands, poor fens and bogs spanning the last 250 years resulted from two processes acting jointly: destruction and origin of habitat patches. Moreover, we found a shift in landscape dynamics in the middle of the last century. Habitat destruction had the most substantial impact on landscape dynamics pre-1950s. This was followed by a period dominated by the origin of new habitat patches, however this was not sufficient to counteract the considerable fragmentation of the landscape. Temporal changes in spatial structure were comparable for the two plateaus. In high Ardenne (Belgium), wet heathlands are semi-natural habitats and are by definition dependent on human management regimes. Consequently, landscape changes likely reflect socio-economic influences acting at a regional scale rather than at a landscape scale (Petit and Lambin, 2002).

\subsection{Influence of spatio-temporal structure on species richness}

Despite complex habitat dynamics and the combination of different aged patches in the current landscapes, the present spatial structure of wet heathland patches exhibited significant effects on species richness. We showed that specialist species richness decreased with a decline in suitable habitat, and increased with a rise in habitat connectivity, even when controlled for habitat quality. The negative effect of habitat area reduction on species richness has generally been interpreted as a consequence of higher extinction rates in small habitats, the so-called area-effect; i.e. the result of an increase in demographic, environmental or genetic stochastic events in small populations (Debinski and Holt, 2000; Holsinger, 2000; Lande, 1993). Nevertheless, we previously found a positive correlation between patch area and diversity in soil types (a surrogate for micro-habitat diversity within patches; unpublished data). A second, but not exclusive, hypothesis for the positive effect of patch area may be a higher capacity of larger patches to host species with slightly different or broader ecological requirements. In contrast to our study, Piessens et al. $(2005,2004)$ found that in northern Belgian heathlands, the isolation of habitat fragments was more important in explaining specialist species richness than patch area. However, these authors controlled patch connectivity for area but not area for connectivity. In addition, they did not control for habitat quality. Due to the different aged patches in our study, habitat quality was likely to vary among patches and influence species richness, biasing the relationships between patch spatial structure and species richness. In particular, we demonstrated that new patches were generally smaller and more isolated than old patches. Since habitat quality and patch spatial structure are significantly related (Cristofoli, 2009), it is important patch quality is considered in the analyses.

Tscharntke et al. (2002) suggested that species do not respond equally to habitat area and isolation. Unlike specialist species, we found generalist species richness was related to connectivity/isolation metrics, not to patch area. A plausible explanation is that generalist species are capable of exploiting habitat types in the surrounding landscape matrix. Low connectivity is expected to have a greater effect on specialist than generalist species (Dupré and Ehrlén, 2002; Jonsen and Fahrig, 1997; Ricketts, 2001). In our study, patch connectivity explained a larger variability component for $R_{\mathrm{SPEC}}$ than for $R_{\mathrm{GEN}}$, but only when connectivity was not controlled for area. This latter result is incongruent with the conclusions of Piessens et al. $(2005,2004)$, and is not comparable to the literature since most studies dealing with the relationships between patch connectivity and species richness do not control for area. Controlling patch connectivity for area, i.e. through the use of a covariate, therefore appears to be important to understand the effects of spatio-temporal habitat dynamics on species diversity. In addition, most studies address either total (e.g. Lindborg and Eriksson, 2004) or specialist species richness (Eriksson et al., 1995; Helm et al., 2006), rarely both. The few studies that have tested for a different effect of habitat structure on generalist versus specialist species have generated inconsistent results (Honnay et al., 1999b; Jonsen and Fahrig, 1997; Krauss et al., 2004), and no generalization can yet be reached. Further research is therefore needed to fully understand the respective role of patch area and connectivity on specialist and generalist species richness.

\subsection{Evidence of an extinction debt}

An underlying effect of fragmentation is the delay with which some populations may suffer local extinction following the onset of the fragmentation process. This temporal distance between fragmentation (cause) and extinction (effect) may lead to an erroneous evaluation of species sensitivity to habitat fragmentation (Adriaens et al., 2006; Gustavsson et al., 2007; Helm et al., 2006; Lindborg and Eriksson, 2004). Although our target habitats are of high conservation value in Europe, no study has explicitly tested for an extinction debt in the plant communities they host. One explanation may be the complex spatio-temporal dynamics of heathland habitats, including the destruction and origin of habitats, as demonstrated in our study. Patches used to estimate extinction debt (i.e. historical patches) should indeed have existed prior to the beginning of the fragmentation process and be of similar age. Patches created more recently, i.e. since the 1950 s or the 1970 s, resulted from an increase and not decrease in patch area, and are therefore not subject to extinction debt per se.

In the present study, historical patches represented only $8.4 \%$ of the number of patches currently present in the landscape, but were an important proportion (32.6\%) of the current habitat area. These historical patches were among the largest, and correspond to core areas for habitat ecological networks. Current landscape structure influenced species richness in these historical patches. However, we also found that past landscape structure contributed significantly to the variation in present species richness. We therefore infer that plant species richness in historical patches of the wet heathland complexes has not fully adapted to substantial habitat fragmentation. At a regional scale, few instances of specialist species extinctions from target habitats have been reported over the past 200 years (Saintenoy-Simon et al., 2003), but our results suggest that such extinctions are likely in the future, at least in historical patches. The life history traits of heathland species (generally a long-term persistent seed bank and long lived species) are such that it may take a considerable length of time before the adverse consequences of habitat loss and fragmentation are apparent.

\subsection{Implications for management}

At the landscape scale, wet heathlands and associated habitat patches differ in age and history as a result of the double dynamics of patch destruction and creation over time. In this context, the disequilibrium between current species richness and spatial structure can be due to either an extinction debt or a colonization credit. These two conditions are related to different ecological mechanisms and can have different management implications. 
Cristofoli et al. (in press) tested the existence of a colonization credit in the same landscapes as the present study. The study suggested that new patches had not yet completely achieved equilibrium between spatial structure and species richness, even though no clear evidence was found for a significant colonization credit in patches created over the last 55 years. This indicated that heathland species are capable of fast spontaneous colonization of new and restored patches, e.g. due to efficient dispersal or to the rescue effect (Brown and Kodric-Brown, 1977). The colonization dynamics after patch creation is therefore encouraging. On the other hand, the present study showed that in historical patches, current species richness was not at equilibrium with present patch configuration. In other words, a number of species are yet to go locally extinct before a new equilibrium is reached between species richness and spatial structure of habitat patches. Local extinctions can be reduced if the area and connectivity and spatial structure of habitat patches are improved in the landscape, which represents a challenge for managers of these fragile and endangered habitats.

\section{Acknowledgments}

S.C. was awarded a Ph.D. grant from the Fund for Research Training in Industry and Agriculture. A.M. has a postdoctoral position at the Belgian Fonds National de la Recherche Scientique (F.R.S. FNRS). This study was supported by the F.R.S.-FNRS (contract FRFC 2.4556.05).

\section{References}

Adriaens, D., Honnay, O., Hermy, M., 2006. No evidence of a plant extinction debt in highly fragmented calcareous grasslands in Belgium. Biol. Conserv. 133, 212-224.

Andrén, H., 1994. Effects of habitat fragmentation on birds and mammals in landscapes with different proportions of suitable habitats: a review. Oikos 71, 355-366.

Arroyo-Mora, J.P., Sánchez-Azefeifa, G.A., Rivard, B., Calvo, J.C., Janzen, D.H., 2004. Dynamics in landscape structure and composition for the Chorotega region, Costa Rica from 1960 to 2000. Agric. Ecosyst. Environ. 106, 27-39.

Bakker, J.P., Berendse, F., 1999. Constraints in the restoration of ecological diversity in grassland and heathland communities. Trends Ecol. Evol. 14, 63-68.

Balmford, A., Bond, W., 2005. Trends in the state of nature and their implications for human well-being. Ecol. Lett. 8, 1218-1234.

Bastin, L., Thomas, C.D., 1999. The distribution of plant species in urban vegetation fragments. Landscape Ecol. 14, 493-507.

Baudry, J., Tatoni, T., 1993. Changes in landscape patterns and vegetation dynamics in Provence, France. Landscape Urban Plan. 24, 153-159.

Brown, J.H., Kodric-Brown, A., 1977. Turnover rates in insular biogeography: effect of immigration on extinction. Ecology 58, 445-449.

Bruun, H.H., 2000. Patterns of species richness in dry grassland patches in an agricultural landscape. Ecography 23, 341-650.

Clicheroux, E., 1985. La forêt de 1800 à nos jours. Organisation de la forêt publique. In: Mardaga, P. (Ed.), Le grand livre de la forêt Wallonne. Soledi, Liège, pp. 34-44.

Collins, B.S., Dunne, K.P., Pickett, S.T.A., 1985. Responses of forest herbs to canopy gaps. In: Pickett, S.T.A., White, S. (Eds.), The Ecology of Natural Disturbance and Plant Dynamics. Academic Press, San Diego, CA, pp. 217-234.

Cousins, S.A., Eriksson, O., 2002. The influence of management history and habitat on plant species richness in a rural hemiboreal landscape, Sweden. Landscape Ecol. 17, 517-529.

Cristofoli, S., 2009. Réponse des espèces a la fragmentation et la restauration des landes humides et habitats associés en haute Ardenne (Belgique): une approche multi-taxonomique. Ph.D. Thesis. University of Liege, Gembloux.

Cristofoli, S., Piqueray, J., Dufrêne, M., Bizoux, J. P., Mahy, G., in press. Colonization credit in restored wet heathlands. Restor. Ecol.

Debinski, D.M., Holt, R.D., 2000. A survey and overview of habitat fragmentation experiments. Conserv. Biol. 14, 342-355.

Dupré, C., Ehrlén, J., 2002. Habitat configuration, species traits and plant distributions. J. Ecol. 90, 796-805.

Duvigneaud, J., 2001. Proposition of a synopsis for the Walloon vegetation groups (with some references related to adjacent regions). Adoxa 1, 23.

Eriksson, A., Eriksson, O., Berglund, H., 1995. Species abundance patterns of plants in Swedish semi-natural pastures. Ecography 18, 310-317.

ESRI, 2002. ArcGIS 8.3 Geographic Information System. Environmental Research Institute Inc., Redlands, CA.

Fahrig, L., 2003. Effects of habitat fragmentation on biodiversity. Ann. Rev. Ecol. Evol. Syst. 34, 487-515.

FSAGx, 2004. Carte Numérique des Sols de Wallonie. Pour le compte de la Région Wallonne (DGA). D’après la Carte des Sols de la Belgique levée $1 / 20,000$, pour le compte de l'Institut pour l'encouragement de la Recherche Scientifique dans l'Industrie et l'Agriculture (IRSIA) (Walloon digital soil map. On the Walloon Region's behalf (DGA). Based on the Belgian soil map drawned at $1 / 20,000$, on the IRSIA's behalf). DGA, Namur, Belgium.

Gimmingham, C.H., 1972. Ecology of Heathland. Chapman \& Hall, London.

Goudie, A., 2005. The Human Impact on the Natural Environment: Past, Present, and Future. Blackwell Publishing, Oxford.

Gustavsson, E., Lennartsson, T., Emanuelsson, M., 2007. Land use more than 200 years ago explains current grassland plant diversity in a Swedish agricultural landscape. Biol. Conserv. 138, 47-59.

Hanski, I., 1994. A practical model of metapopulation dynamics. J. Anim. Ecol. 63, 151-162.

Hanski, I., Ovaskainen, O., 2002. Extinction debt at extinction threshold. Conserv. Biol. 16, 666-673.

Helm, A., Hanski, I., Pärtel, M., 2006. Slow response of plant species richness to habitat loss and fragmentation. Ecol. Lett. 9, 72-77.

Holsinger, K.E., 2000. Demography and extinction in small populations. In: Young, A.G., Clarke, G.M. (Eds.), Genetics, Demography and Viability of Fragmented Populations. Cambridge University Press, Cambridge, pp. 55-74.

Honnay, O., Endels, P., Vereecken, H., Hermy, M., 1999a. The role of patch area and habitat diversity in explaining native plant species richness in disturbed suburban forest patches in northern Belgium. Divers.Distrib. 5, 129-141.

Honnay, O., Hermy, M., Coppin, P., 1999b. Effects of area, age and diversity of forest patches in Belgium on plant species richness, and implications for conservation and reforestation. Biol. Conserv. 87, 73-84.

Jacquemyn, H., Butaye, J., Hermy, M., 2003. Influence of environmental and spatial variables on regional distribution of forest plant species in a fragmented and changing landscape. Ecography 26, 768-776.

Jonsen, I.D., Fahrig, L., 1997. Response of generalist and specialist insect herbivores to landscape spatial structure. Landscape Ecol. 12, 185-197.

Kolb, A., Diekmann, M., 2005. Effects of life-history traits on responses of plant species to forest fragmentation. Conserv. Biol. 19, 929-938.

Krauss, J., Klein, A.M., Steffan-Dewenter, I., Tscarntke, T., 2004. Effects of habitat area, isolation, and landscape diversity on plant species of calcareous grasslands. Biodivers. Conserv. 13, 1427-1439.

Krüger, A.M., Hellwig, F.H., Oberprieler, C., 2002. Genetic diversity in natural and anthropogenic inland populations of salt-tolerant plants: random amplified polymorphic DNA analyses of Aster tripolium L. (Compositae) and Salicornia ramosissima Woods (Chenopodiaceae). Mol. Ecol. 11, 1647-1655.

Lambinon, J., De Langhe, J.-E., Delvosalle, L., Duvigneaud, J., 2004. Nouvelle flore de la Belgique, du Grand-Duché de Luxembourg, du nord de la France et des régions voisines (Ptéridophytes et Spermatophytes) (new flora of Belgium, Luxembourg, north of France and adjacent regions (Pteridopthytes and Spermatohpytes)). Editions du Patrimoine du jardin botanique national de Belgique, Meise.

Lande, R., 1993. Risks of population extinction from demographic and environmental stochasticity and random catastrophes. Am. Nat. 142, 911-927.

Lebrun, J., Noirfalise, A., Heinemann, P., Vanden berghen, C., 1949. Les associations végétales de Belgique. B. Soc. Roy. Bot. Belg. 82, 105-207.

Lindborg, R., 2007. Evaluating the distribution of plant life-history traits in relation to current and historical landscape configurations. J. Ecol. 95, 555-565.

Lindborg, R., Eriksson, O., 2004. Historical landscape connectivity affects present plant species diversity. Ecology 85, 1840-1845.

Moilanen, A., Nieminen, M., 2002. Simple connectivity measures in spatial ecology. Ecology 83, 1131-1145.

Petit, C., Lambin, E.F., 2002. Long-term land-cover changes in the Belgian Ardennes (1775-1929): model-based reconstruction vs. historical maps. Glob. Change Biol. 8, 616-630.

Piessens, K., Hermy, M., 2006. Does the heathland flora in north-western Belgium show an extinction debt? Biol. Conserv. 132, 382-394.

Piessens, K., Honnay, O., Nackaerts, K., Hermy, M., 2004. Plant species richness and composition of heathland relics in north-western Belgium: evidence for a rescue-effect? J. Biogeogr. 31, 1683-1692.

Piessens, K., Honnay, O., Hermy, M., 2005. The role of fragment area and isolation in the conservation of heathland species. Biol. Conserv. 122, 61-69.

Pimm, S.L., Jones, H.L., Diamond, J., 1988. On the risk of extinction. Am. Nat. 132, 757-785.

Ricketts, T.H., 2001. The matrix matters: effective isolation in fragmented landscapes. Am. Nat. 158, 88-99.

Ricklefs, R.E., 2004. A comprehensive framework for global patterns in biodiversity. Ecol. Lett. 7, 1-15.

Rodwell, J.S., 1991. British plant communities. Cambridge University Press.

Saintenoy-Simon, J., Duvigneaud, J., Rouxhet, S., 2003. Flore et végétation du plateau de Saint-Hubert (flora and vegetation of the Saint-Hubert plateau). Adoxa 39, $1-19$.

Tscharntke, T., Steffan-Dewenter, I., Kruess, A., Thies, C., 2002. Characteristics of insect populations on habitat fragments: a mini-review. Ecol. Res. 17, 229239.

Turner, M.G., Gardner, R.H., O'Neill, R.V., 2001. Landscape Ecology in Theory and Practice: Pattern and Process. Springer-Verlag, New York, USA.

Watt, A.S., 1955. Bracken versus heather, a study in plant sociology. J. Ecol. 43 490-506.

Webb, N.R., 1998. The traditional management of European heathlands. J. Appl. Ecol. 35, 987-990.

Webb, N.R., 2002. Atlantic heathlands. In: Perrow, M.R., Davy, A.J. (Eds.), Handbook of Ecological Restoration. Principles of Restoration. Cambridge University Press, Cambridge, pp. 401-418. 